\title{
Reshaping Assessment Practices in a Philippine Teacher Education Institution during the Coronavirus Disease 2019 Crisis
}

\author{
Michael Bobias Cahapay ${ }^{1 *}$ \\ ${ }^{1}$ College of Education, Mindanao State University, General Santos City, PHILIPPINES \\ *Corresponding Author: mbcahapay@up.edu.ph
}

Citation: Cahapay, M. B. (2020). Reshaping Assessment Practices in a Philippine Teacher Education Institution during the Coronavirus Disease 2019 Crisis. Pedagogical Research, 5(4), em0079. https://doi.org/10.29333/pr/8535

\begin{tabular}{|c|c|}
\hline ARTICLE INFO & ABSTRACT \\
\hline Received: 10 May 2020 & This case study analyzes the assessment practices in a Teacher Education Institution (TEI) in the Philippines during \\
\hline Accepted: 27 Jul. 2020 & $\begin{array}{l}\text { the Coronavirus Disease } 2019 \text { (COVID-19) crisis. The results showed that assessment practices were contextually } \\
\text { reshaped as classes were suspended at the time when assessment evidence cannot be computed; limited internet } \\
\text { connectivity posed logistical issues to move to online assessment; and institutional tradition of maintaining } \\
\text { quality draws a major concern. As a consequence, changes were evident in the grading component solely focusing } \\
\text { on student attendance; grading system shifting to descriptive binary; requirements for laboratory and research } \\
\text { works significantly modified; and exclusion of grades earned in the current semester from the computation of } \\
\text { grade point average. Drawing lessons from this case study, it is recommended that in reshaping assessment } \\
\text { practices in this time, different contexts must be cogently considered, so that reasonable changes will be better } \\
\text { understood. }\end{array}$ \\
\hline
\end{tabular}

Keywords: educational assessment, teacher education, higher education, COVID-19, single case study

\section{INTRODUCTION}

Since the outbreak of COVID-19 from Wuhan, China (Phelan, Katz, \& Gostin, 2020), governments around the world have closed its systems, including education, in the attempt to slow down the community transmission of the disease. The Global Education Monitoring Report (2020) expressed issues in educational aspects, one of which is on assessment practices. It is observed that schools have adopted new assessment practices such as using previous grades from mock exams, applying observational assessments of teachers, and considering prior grade expectations. These emerging assessment practices, however, have put education stakeholders in a state of quandary and even discord.

As a response, the UNESCO (2020) recently established guidelines for higher education institutions of its member states. It urged for the development of strategies that will promote innovation of assessment practices. Assessment is an important instructional component that collects information as regards the knowledge, skills, values that students have learned (Allen, 2004). This information can be obtained from directly examining student work to assess the achievement of learning outcomes (Kuh, Jankowski, \& Ikenberry, 2014). However, considering the current global crisis restricting normal conditions of learning, assessment practices have to be reconsidered from different perspectives.

An emerging body of researches has been published to discuss how education and assessment practices are being reshaped in the light of the present COVID-19 condition (e.g., see Bernhard \& Camins, 2020 on exploring telesupervision in practicum training; Berry \& Kitchen, 2020 on reconsidering education to create new transformations; Hall et al., 2020 on assisting competency-based medical education; Li et al, 2020 on employing blended synchronous teaching and learning; Marasi et al., 2020 on analyzing teacher satisfaction with virtual teaching; Marin et al., 2020 on proposing a unified framework for learning; Oladipo \& Okiki, 2020 on assessing the contribution of online information resources; Samson, 2020 on describing learner behaviors in the blended synchronous subject).

As regards how assessment practices are currently being reshaped in the Philippine higher education, the Commission on Higher Education (CHED) issued the COVID Advisory No. 6 series of 2020 articulating guidelines regarding assessment. It authorized the higher education institutions to determine how to best meet the contact hour requirements for the completion of a subject or degree program. It further urged to undertake alternative assessments and remediations and consider student assessment and computation of grades to be based on current student records and school academic policies.

Such guideline was general and Philippine tertiary schools have to adopt different strategies to put an assessment of student learning in place. Some of these strategies include mass promotions, waived requirements, and deferred grades (Yumol, 2020). 
There are recent reports that students are seriously faced by challenges on technology access, financial stability, and emotional support especially those who are stranded (Alvarez, 2020; Cahapay, 2020; Tria, 2020), so strategies have to be undertaken. Human compassion aside, the question that has generated different opinions from the education stakeholders, however, is the extent to which these strategies will be reasonable representations of student performance (Mateo, 2020).

Besides the differences in the opinions of education stakeholders about the changes in assessment practices, contexts play a significant role. Within the case of a TEI in the Philippines, these contexts involve time, resources, and culture that interplay with the assessment practices. With the ongoing COVID-19 pandemic, a focused study is sought to unravel the changes and contexts that surround the assessment practices.

Thus, this study generally sought to analyze the assessment practices of a TEI in the Philippines during the COVID-19 crisis.

\section{METHOD}

\section{Research Design}

A case study is employed as a research design in this work. It is defined as an approach used to generate an understanding of a complex issue in a context (Crowe et al., 2011). It is an established research design that is used extensively in a wide variety of disciplines such as education. The current paper intended to analyze the assessment practices with a purpose by extension to understand the changes amid the COVID-19 pandemic from the single case of a TEI. The case study is an appropriate research design to attain this research goal.

\section{Case Context}

The case context of this study is based on a single instrumental case study. It is a case study in which the researcher focuses on a single issue then selects a single case to illustrate the issue (Creswell, 2013). The current research situated the issue on assessment practices amid COVID-19 pandemic in a TEI in the Philippines.

\section{Unit of Analysis}

Documents, as a record of human activities, provide a valuable data source for analysis in this study. This study specifically analyzed a type of document called public records, referring to the official, ongoing records of an activity (Mills, Durepos, \& Wiebe, 2010). It included in this work the relevant instructional plans, the program of study, student handbook, memorandum orders, and implementing guidelines that contain information about assessment practices.

\section{Data Analysis Technique}

Moreover, document analysis was applied to carefully examine the emerging assessment practices in the context. Document analysis is a form of qualitative research technique in which documents are deciphered by the investigator to give meaning around a topic. It incorporates the coding of content into themes the same way interview transcripts are analyzed (Bowen, 2009).

\section{Data Presentation Framework}

The framework followed to present the data of this study was adopted from Creswell (2013). He suggested that in the presentation, a case study should report the description of the case and then the development of the theme about the case. This framework proposes a practical and cogent approach of data presentation, hence followed in this study.

\section{RESULTS}

\section{Case Description}

The initial impact of COVID-19 in education in the Philippines was experienced when classes in all levels in Metro Manila were suspended from Tuesday, March 10, to Saturday, March 14, as President Rodrigo Duterte announced on March 9. The President said that the suspension was necessary to appraise the incubation of COVID-19, the disease caused by the novel coronavirus. On March 12, classes were further suspended in Metro Manila for a month when the President elevated the status of the COVID-19 pandemic in the entire country as part of a partial lockdown austerity measure. This was then followed by massive class suspensions of all education institutions all over the country.

Through Advisory No. 3 dated March 11, 2020, the CHED issued guidelines that have direct implications to the assessment practices in higher education institutions. It directed higher education institutions to facilitate alternative activities to enable students to complete required practicum; deploy available remote learning, virtual learning, and other alternative modalities of instructional implementation if resources allow; and evaluate students based on available indicators or assessment evidence as of this time.

On March 13, 2020, CHED issued Advisory No. 6 urging tertiary institutions anew to arrange flexible learning and other alternative modalities of instruction to offset for traditional campus learning. On the other hand, during the continuing community quarantine, CHED authorized institutions to consider ways how to meet the requirements for the completion of a subject or degree. It suggested that schools may employ responsive approaches to student assessment. Furthermore, it cautioned that instructional implementation during the extended community quarantine should consider the resources of the students. 
These advisories had allowed higher education institutions to exercise their freedom on how student assessment may be conducted. The current TEl under the study is one of these higher education institutions in the Philippines. It can be gleaned from professional experiences, document analyses, and direct observations that reshaping its assessment practices had to consider its contexts of time, resources, and culture.

First, unlike other colleges and universities in the region, the TEI is the few of those institutions that changed the school calendar from June-October to August-December for the first semester and from November-March to January-May for the second semester. Thus, as far as immediate assessment needs are concerned, comparison with other colleges and universities following the June-March calendar have lesser concerns to handle as they were about to end the semester in a week or two. Their students have almost completed most of the assessment activities to obtain grades for the semester. There were almost no changes made as regards their assessment components and grading system. The case of the TEI under the study is different. It was just in the middle of the semester, thus computation of a grade that is reasonable for a final grade is apparently impossible.

Second, the TEI has to consider both the capacity of itself and its students in the shift of instruction, including assessment practices, to online. While the TEI may be able to find ways in strengthening its capacity to deliver alternative modes of assessment through the internet, it may not be the same for most of its students. A rapid online survey involving selected students was conducted shortly after the school closure. It showed that most of the students are not ready for online instruction. They cited the primary hindering factor as poor internet signal. When asked what instructional modality they find convenient this time, most students cited modular instruction. These are only some thoughts that need to be contemplated in designing instruction in general. When putting the situation in a comparative perspective, guidelines issued by other colleges and universities ordered for online completion some unfinished requirements. This action can be attributed to the strong logistical capacities of the said institutions and their students.

Third, concerns from the TEI faculty members stemming from the institutional culture had to be considered also in decisions about what assessment practices should be adopted. Some members seemed to express endorsement for mass promotion of students, citing human compassion and connectivity restriction in these difficult times. On the other hand, other members appeared to be reluctant with the idea, justifying that mass promotion will have repercussions in the instruction in the higher year levels and will eventually sacrifice the tradition of institutional quality. This issue appears to be less pronounced in other colleges and universities in which assessment of their students was not drastically affected. It can be observed in their recently issued implementing guidelines that the essential elements of their grading components, grading system, and grade computation have remained more or less the same.

\section{Case Themes}

The following themes concerning changes in the assessment practices emerged from the analysis of relevant documents:

Theme 1: Grading components. Based on the instructional plans reviewed, the grading components in the TEl by practice are generally a combination of traditional and authentic strategies. The traditional assessment strategies mainly include quizzes and examinations which weigh between $15 \%$ and $30 \%$ of the total grade in a course. On the other hand, the alternative assessment strategies like participations, projects, demonstrations, and papers account for between $10 \%$ and $20 \%$.

As it was provided in the new implementing guidelines, "attendance from January to March shall be the basis for giving a passing grade" (p.1). Looking at this stipulated change, the administration directly endorsed a major and single grading component. This grading component solely focused on student attendance. Such a single grading component is based on the class hours attended by the students in the months before the declaration of school closure.

Theme 2: Grading System. As reviewed in the student handbook, the grading system of the TEl is numerical except for the final course on research work. The courses grouped as concepts and theories, methods and strategies, and laboratory work follow the numerical grading system. This numerical grading system ranges from 1 which is excellent to 5 which is failed. On the other hand, the descriptive grading system which is specifically for the final course on research work observes descriptive range from $P$ for passed and $\mathrm{F}$ for failed.

In the new implementing guidelines, the grading system was changed to alphabetic binary: Passed or Dropped. It could be quoted that, "students shall only be given either a grade of P (Passed) or DRP (Dropped)" and that "no failing grades shall be given" (p.1). As attendance is the sole grading criterion, a student who attended at least $80 \%$ of the total class hours is given the grade of Passed. The students are otherwise given a mark of Dropped from the course if the minimum percentage of attendance is not satisfied.

Theme 3: Laboratory work completion. The laboratory work in this TEl context is considered as the student teaching internship that is done in the laboratory school. As reflected in the program of study, it is usually taken during the second semester of the final year of the students from January to May. It means that all of the students in this course are graduating students. Aside from the demonstration and paper works, a major criterion of this course is the completion of a minimum of 280 hours of teaching duties in the laboratory school.

Considering the school closure that took effect in March, the new implementing guidelines order that "students under OJT or practice teaching for the $2^{\text {nd }}$ semester of AY 2019-2020 are no longer required to complete their remaining hours of service" (p. 3). This rule, in turn, waives all other requirements such as paper works that are usually submitted when the laboratory work hours have been completed at the end of the semester.

Theme 4: Research work completion. The review of the program of study shows that a course assigned for the completion of the undergraduate research work is part of the requirements to complete the program of the TEI. This research course requires 
the student to implement the initially proposed research to gather the needed data. By practice, the assessment of the research work goes through oral examination and submission of bound copy duly signed by the thesis adviser and the panel members.

The new implementing guidelines state three important changes in the assessment of the research course. First, students officially enrolled in the research course shall be given a grade of Passed upon evaluation that the research was accomplished at least $50 \%$. Second, students are not required for the oral examination. Third, submission of the bound copies shall be required for the release of the transcript of records after graduation. With this new assessment practice, it should be further noted that "thesis advisers are called upon to exercise leniency in their evaluation of the student researches due to the loss of opportunity to work" (p. 3).

Theme 5: GPA Computation. As the usual practice in most TEls and other fields, the student handbook of the TEI considers GPA as the computed average of all the grades in the courses required in the program. However, the changes in the grading system into alphabetic binary grading make numerical computation impossible. These changes have also immediate implications as to how the computation of GPA for graduating and honor students will be reconsidered.

Thus, in the new implementing guidelines, the computation of the GPA will not include the grades earned during the suspended semester. However, it is noted that the units earned shall be credited. To directly quote, "grades in the $2^{\text {nd }}$ semester of AY 2019-2020 shall not be included in the computation of grades" and that "units earned shall be officially credited for the counting of percentage of units earned in the university" (p. 4). The guideline further provides the same rule for the graduating students and in determining honors or awards. Furthermore, qualified students shall still be entitled to receive their respective honors or awards.

\section{DISCUSSION}

As a result of the challenges posed by the COVID-19 crisis, several assessment practices in education have been adopted. There is no single solution that suits all; assessment practices are expected to differ across contexts. As such, this paper focused on the context of a TEI in the Philippines and on this period of COVID-19 crisis. The results present four major points of discussion about assessment practices. The attendance as a grade component, binary alphabetic grading scale, grading reliability, and grade point average computation highlight the issues that demand discussion.

As regards grading components, there has been a movement in the past decades from traditional assessment toward alternative assessment (Dikli, 2003). This observation and the application of both types of assessment have been documented in different researches (e.g. Dikli, 2003; Nasab, 2015; Reeves, 2000). However, attendance is mentioned nowhere as a part of either traditional or alternative assessment. Under the COVID-19 crisis, the argument for attendance as a part of the grading component is classical in the light that attendance, as a consequence, does not constitute learning. Silver (2018) argued that attendance contaminates grades as a pure amount of performance.

Considering the current worldwide crisis, it seemed schools have found a solution to consider attendance as a major assessment component to arrive at assessment evidence. It is readily available and easy to measure. On the other hand, some schools have adopted other different grade components such as using previous grades from mock exams, observational assessments of teachers, and prior grade expectations (Global Monitoring Report, 2020).

Furthermore, most schools today use a numeric grading system with alphabetic equivalent and descriptions (Olivares, 2018). Within each grading system, there are also variants. The advantages and disadvantages of these grading systems and their variants are debated in the context of student motivation (Barnes \& Buring, 2012). Researches have been further conducted to determine the effects of different grading systems on the students and the results are varied (e.g. Frank \& Feeney, 2006; McClure \& Spector, 2005; Wilamowsky, Dickman, \& Epstein, 2008).

With the recent public health emergency worldwide, many higher education institutions, including the TEl under study, have decided to change their grading systems. For example, schools have adopted a pass or fail grading system (Farrington, 2020). This recommendation is supported by advantages, citing it is not fair to arrive at a judgment of failure to consider that students have not been allowed for a complete semester to make their grades (Mateo, 2020). On the other hand, such a practice can have disadvantages. It is argued that instead of relieving the problem of sustaining high grades, this judgment would detach the motivation that students need to strive for high grades (Dilanchyan, 2020).

On the other hand, adjustments to the point of leniency error in the completion of course works are echoed in the fear of some education stakeholders that it will reduce grade reliability. Theoretically, leniency error is a condition in which the teacher is too indulgent, and all students achieve high passing scores. It is considered as one of the threats to grade reliability (Nitko \& Brookhart, 2014). This issue is compounded by other grading issues related to the validity and integrity of grades raised in the researches of Allen (2005) and Saddler (2009) respectively. They reach a common point that grades should reflect what learning is assessed and how commensurate is the grade with the student performance.

Current practices considering leniency in the compliance of course requirements have a disadvantage in the light of leniency error. Many schools, like in the current case of the TEI, have recommended teachers to be considerate in their assessment practices. This dialog on assessment has extended deadlines for paper works, abandon consequences for deferred submissions, and reduced chunks of requirements (Flaherty, 2020). While it may endanger grade reliability, validity or integrity, the advantage of such new practice is seen by some scholars as a point of human consideration, accounting for the lost opportunities of learning for students to fairly work for the grade that they deserve (Mateo, 2020). 
Lastly, it cannot be denied that the COVID-19 restriction is endangering future opportunities that require transcripts with a strong GPA for students. When a student will move, for example, to graduate school or work field, Burke (2020) expressed concerns about how a mark of "pass" or "fail" in the transcript of records is going to leave an impression to an admissions officer or a hiring officer.

As such practice is implemented in the present context of the school under the study, Sdvizhkov (2020) recommended excluding the term or courses affected by COVID-19 from the computation of academic standing. She further indicated to create a transcript denotation that remarks COVID-19 circumstances and remove all courses during impacted terms from consideration for standard academic honors and distinctions. This recommendation seemed to be widely practiced in many schools. It is an approach seen to help explain assessment records which is important in the current assessment needs and the future endeavors of the students.

Considering the above discussion, this paper provides important contributions in education as far as the COVID-19 situation is regarded. As this article is written in the moment of the COVID-19 crisis, its themes exploring the changes in the assessment practices are applicable as points of further investigation in other contexts. The discussion also sought to reconsider traditional assumptions about assessment, thus create transformative opportunities.

\section{CONCLUSION}

The COVID-19 crisis is creating drastic changes in the assessment practices of education systems and institutions. Within the case of a Philippine TEl, these changes were made within the temporal, logistical, and cultural contexts. These changes were evident in the grading components, grading system, laboratory work completion, research work completion, and grade point average computation.

Considering the temporal setting, the class suspension was made coincidentally in the middle of the semester, making it impossible to compute for a reasonable final grade. The issue of internet accessibility further posed logistical hindrances to shift student assessment to online. Some differences in the opinions of the faculty members were also noted mainly revolving around the cultural tradition of maintaining quality. As such, this case study provides theoretical evidence as regards the different contexts that must be considered when the assessment component of a curriculum is redeveloped.

Consequently, changes were observed in the grading components which used to be multiple and have now become single, focusing on student attendance. The grading system has likewise shifted from numerical to descriptive binary. On the other hand, the requirements to complete laboratory and research works have been significantly modified. It was also decided that grades earned during the current semester would not be included in the computation of grade point average. With this conclusion, this work presents practical significance that supports innovations in assessment practices as far as the current crisis is concerned.

This work focused on a single instrumental case. Hence, it is suggested that further related studies should be made in other fields and levels of education. It also heavily relied on documents and professional observations. As such, multiple sources of data such as interviews should be considered in future works. Furthermore, when examining assessment practices in the light of the COVID-19 crisis or other significant events, it is generally recommended that distinctive contexts must be cogently considered, so that reasonable changes will be better understood.

\section{REFERENCES}

Allen, J. D. (2005). Grades as valid measures of academic achievement of classroom learning. The Clearing House, 78(5), $218-223$. https://doi.org/10.3200/TCHS.78.5.218-223

Allen, M. J. (2004). Assessing academic programs in higher education. San Francisco: Jossey- Bass.

Alvarez, A. Jr. (2020). The phenomenon of learning at a distance through emergency remote teaching amidst the pandemic crisis. Asian Journal of Distance Education, 15(1), 144-153. https://doi.org/10.5281/zenodo.3881529

Barnes, K. D., \& Buring, S. M. (2012). The effect of various grading scales on student grade point averages. American Journal of Pharmaceutical Education, 76(3), 41. https://doi.org/10.5688/ajpe76341

Bernhard, P. A., \& Camins, J. S. (2020). Supervision from afar: Trainees' perspectives on telesupervision. Counselling Psychology Quarterly. Published online: 25 May 2020. https://doi.org/10.1080/09515070.2020.1770697

Berry, A., \& Kitchen, J. (2020). The Role of self-study in times of radical change. Studying Teacher Education, 16(2), $123-126$. https://doi.org/10.1080/17425964.2020.1777763

Bowen, G. A. (2009). Document analysis as a qualitative research method. Qualitative Research Journal, 9(2), 27-40. https://doi.org/10.3316/qrj0902027

Burke, L. (2020, April 13). The asterisk semester. Inside Higher Ed. Retrieved from https://www.insidehighered.com/news/2020/04/13/how-will-passfail-affect-students-future

Cahapay, M. B. (2020). Stranded college students amid COVID-19 pandemic: An existential phenomenology. Journal of Loss and Trauma, 25(6-7), 598-604. https://doi.org/10.1080/15325024.2020.1770955 
Commission on Higher Education (2020). Memoranda about COVID-19. Retrieved from https://ched.gov.ph/blog/2020/03/12/guidelines-for-the-prevention-control-and-mitigation-of-the-spread-of-the-2019novel-coronavirus-acute-respiratory-disease-in-higher-education-institutions/

Creswell, J. W. (2013). Qualitative inquiry \& research design choosing among five approaches (3rd ed.). Thousand Oaks, CA: SAGE.

Crowe S., Cresswell, K., Robertson, A., Huby, G., Avery, A., \& Sheikh, A. (2011). The case study approach. BMC Medical Research Methodology, 11(1), 100. https://doi.org/10.1186/1471-2288-11-100

Dikli, S. (2003). Assessment at a distance: Traditional vs. alternative assessments. The Turkish Online Journal of Educational Technology, 2(3), 13-19. Retrieved from http://www.tojet.net/articles/v2i3/232.pdf

Dilanchyan, H. (2020, March 31). The pass/fail grading system could severely affect your GPA. Chimes. Retrieved from https://chimesnewspaper.com/47867/opinions/the-pass-fail-grading-system-could-severely-affect-your-gpa/

Farrington, R. (2020, March 30). Colleges go to pass-fail due to Coronavirus concerns: What does this mean for students. Forbes. Retrieved from https://www.forbes.com/sites/robertfarrington/2020/03/30/colleges-go-to-pass-fail-due-to-coronavirusconcerns-what-does-this-mean-for-students/\#620c39aa7eaa

Flaherty, (2020, April 23). Grading for a pandemic. Inside Higher Ed. Retrieved from https://www.insidehighered.com/news/2020/04/23/how-lenient-or-not-should-professors-be-students-right-now

Frank, M. L., \& Feeney, L. (2006). Plus/minus grading: a within instructor comparison. College Student Journal, 40(4), 852-856. Retrieved from https://eric.ed.gov/?id=EJ765386

Global Education Monitoring Report (2020). Could coronavirus shape the way assessments work forever? [Blog post]. Retrieved from https://gemreportunesco.wordpress.com/2020/03/20/could-coronavirus-shape-the-way-assessments-work-forever/

Hall, A. K., Nousiainen, M. T., Campisi, P., Dagnone, J. D., Frank, J. R., Kroeker, K. I., Brzezina, S., Purdy, E., \& Oswald, A. (2020). Training disrupted: Practical tips for supporting competency-based medical education during the COVID-19 pandemic. Medical Teacher, 42(7), 756-761. https://doi.org/10.1080/0142159X.2020.1766669

Kuh, G. D., Jankowski, N., \& Ikenberry, S. O. (2014). Knowing what students know and can do: The current state of learning outcomes assessment in U.S. colleges and universities. Urbana: University of Illinois and Indiana University, National Institute for Learning Outcomes Assessment.

Li, X., Yang, Y., Chu, S. K. W., Zainuddin, Z., \& Zhang, Y. (2020). Applying blended synchronous teaching and learning for flexible learning in higher education: An action research study at a university in Hong Kong. Asia Pacific Journal of Education. Published online: 01 Jun 2020. https://doi.org/10.1080/02188791.2020.1766417

Marasi, S., Jones, B., \& Parker, J. M. (2020). Faculty satisfaction with online teaching: a comprehensive study with American faculty. Studies in Higher Education. Published online: 22 May 2020. https://doi.org/10.1080/03075079.2020.1767050

Marin, A., Taylor, A. K., Shapiro, B. R., \& Hall, R. (2020). Why Learning on the Move: Intersecting research pathways for mobility, learning and teaching. Cognition and Instruction, 38(3), 265-280. https://doi.org/10.1080/07370008.2020.1769100

Mateo, J. (2020, April 16). Automatic passing mark, online classes and graduation rites: schools face COVID-19 challenges. The Philippine Star. Retrieved from https://www.onenews.ph/automatic-passing-mark-online-classes-and-graduation-ritesschools-face-covid-19-challenges-2

McClure, J. E., \& Spector, L. C. (2005). Plus/minus grading and motivation: An empirical study of student choice and performance. Assessment and Evaluation Higher Education, 30(6), 571-579. https://doi.org/10.1080/02602930500260605

Mills, A. J., Durepos, G., \& Wiebe, E. (2010). Encyclopedia of case study research. Thousand Oaks, CA: SAGE. https://doi.org/10.4135/9781412957397

Nasab, F. G. (2015). Alternative versus traditional assessment. Journal of Applied Linguistics and Language Research, 2(6), 165-178. Retrieved from http://www.jallr.com/index.php/JALLR/article/view/136

Nitko, A. J., \& Brookhart, S. M. (2014). Educational assessment of students (8 $8^{\text {th }}$ ed.). Pearson Education: New York.

Oladip, A. J., \& Okiki, O. C. (2020). Assessment of the contribution of online information resources in open distance learning mode to the development of lifelong learning in South-West, Nigeria. Journal of Library \& Information Services in Distance Learning. Published online: 05 Jun 2020. https://doi.org/10.1080/1533290X.2020.1772940

Olivares, M. (2018, May 31). The American grading system from A to $F$ and GPA [Blog post]. Retrieved from https://www.mooxye.com/blog/en/american-grading-system-and-gpa/

Phelan, A. L., Katz, R., \& Gostin, L. O. (2020). The novel coronavirus originating in Wuhan, China: challenges for global health governance. JAMA, 323(8), 709-710. https://doi.org/10.1001/jama.2020.1097

Reeves, T. C. (2000). Alternative assessment approaches for online learning environments in higher education. Educational Computing Research, 3(1), 101-111. https://doi.org/10.2190/gymq-78fa-wmtx-j06c

Saddler, D. R. (2009). Grade integrity and the representation of academic achievement. Studies in Higher Education, 34(7), 807-826. https://doi.org/10.1080/03075070802706553

Samson, P. J. (2020). Student behaviors in a blended synchronous course. Journal of Geoscience Education. Published online: 04 Jun 2020. https://doi.org/10.1080/10899995.2020.1768002 
Sdvizhkov, H. (2020, April 8). 3 ways institutions should adjust student evaluation and grading policies. EAB. Retrieved from https://eab.com/insights/expert-insight/academic-affairs/3-ways-institutions-should-adjust-student-evaluation-andgrading-policies/

Silver, J. S. (2018, August 19). The Contamination of Student Assessment. Inside Higher Ed. Retrieved from https://www.insidehighered.com/views/2018/08/09/why-faculty-shouldnt-factor-class-attendance-and-participation-finalgrades-opinion

Tria, J. Z. (2020). The COVID-19 pandemic through the lens of education in the Philippines: The new normal. International Journal of Pedagogical Development and Lifelong Learning, 1(1), ep2001. https://doi.org/10.30935/ijpdll/8311

UNESCO. (2020). COVID-19 and higher education: Today and tomorrow. Paris: UNESCO.

Wilamowsky, Y., Dickman, B. H., \& Epstein, S. (2008). The effect of plus/minus grading on the GPA. Journal College Teaching and Learning, 5(9), 1-4. https://doi.org/10.19030/tlc.v5i9.1228

Yumol, D. T. (2020, April 22). All PLM students to get passing mark amid COVID-19 crisis. CNN Philippines. Retrieved from https://www.cnn.ph/news/2020/4/22/all-plm-students-get-passing-mark-covid-crisis.html 